\title{
The Role of Share-Cropping and Work-Parties in Bolstering Social Relations Among Peasants at Gqumahashe, Alice District
}

\author{
Mzwandile Paul Komanisi
}

\author{
Faculty of Social Sciences and Humanities, Department of Sociology and Anthropology, \\ University of Fort Hare, Alice, 5700 \\ Email:mkomanisi@ufh.ac.za
}

Doi:10.5901/mjss.2014.v5n23p1849

\begin{abstract}
The overall aim of this article is to present empirical material regarding the role of share- cropping and work-parties in cementing social relations among peasants of Gqumahashe village in Alice District. The article also offers a scholarship review on social relations and crop production. Empirical evidence presented here was collected through in-depth interviews, participant observation and focus group discussions. Key among the findings is that share-cropping has benefits and costs for both the owners and croppers. Another major empirical finding of the study is that reciprocated labour sustains family agricultural output .In conclusion, the article contends that share-cropping and work- parties bind people in affable social relations.
\end{abstract}

Keywords: social relations share- cropping, work- parties, reciprocated labour, agricultural output, enhance, togetherness.

\section{Introduction}

A large literature (Douglas, 1971; Brown and Mussel, 1984; Mennell, 1985; Coe, 1997 \& Gumerman, 1997) has demonstrated that food is fundamentally social. The scholarship of these researchers highlights that social relations are defined and maintained through food. The assertion put forward by the latter is that food should not be evaluated for the single purpose of describing diet and nutrition. The argument advanced by these scholars is that a meal is an occasion that cultivates and preserves relationships among participants and nonparticipants. In a similar vein, empirical material of Tavuyanago, Mutami \& Mbenene (2010) suggests that among the Shona co-operative work or work-parties bind people in affable social relations, especially relations of production.

Based on primary data and observations during the fieldwork, this article seeks to chronicle how crop- sharing and work-parties bolster affable social relations among the peasants of Gqumahashe village in Alice district.

\section{Methodology}

This study adopted empirical research strategy. Empirical research strategy relies on primary data and has been defined by Remenyi and Money (2012, p.71) as:

"Empirical research involves the acquisition of primary data which has been described by researchers as sense perceived data. However, not all issues which need to be researched are observable through sense perceived data. Examples of situations which involve non-observable data are particle physics and genetic engineering. Nonetheless research involving situations where there is a clear understanding of how cause and effect directly impacts data is acceptable for the purposes of empirical research. There are other aspects of empirical research where data is not perceived or experienced directly by the researcher but is obtained by accounts from others. Research which is conducted using interviews or in focus groups is regarded as empirical and it is clear that the researcher has not had a direct experience of the phenomenon. Data collected by questionnaire is the same category."

The researcher espoused empirical research strategy because he sought to draw on experience or observation of primary evidence in order to understand a phenomenon being studied. He went out and met the study population to collect new evidence in some sort of way. 


\subsection{Research Design}

\subsubsection{Ethnography}

There are two sources of cultural data about a particular people: the living members of the society and written accounts or other records about that group of people. Collecting cultural data by studying and interviewing living members of a society is called ethnographic fieldwork (Peoples \& Bailey, 2012). Andreatta \& Ferraro (2012) paint a similar picture by noting that cultural anthropologists collect their primary data by living with the people they study. They learn the language of the people, ask questions, survey the environment, inventory material possessions, and spend long periods of time observing and participating in everyday life. Such a work is called ethnography.

This study adopted qualitative field research paradigm, following naturalistic approach. Babbie (2013) ascertains that Naturalism is an old tradition in qualitative research. He extrapolates that one of the first and best-known scholarships that illuminates this research tradition is William Foote Whyte's ethnography of Cornerville, in his book Street Corner Society (1943). Like other naturalists, Whyte believed that in order to learn fully about social life on the streets, he needed to become more of an insider (Babbie, 2013). The argument advanced by Babbie (2013) here is that the naturalist approach is grounded on telling peoples' narratives the way "really are", not the way the ethnographer understands them.

The investigation adopted qualitative research approach because the aim of the researcher was to get a richly detailed picture of life among the study population. The strengths of qualitative approach as advocated by Miles, Huberman \& Saldana (2014), has also inspired the researcher to choose qualitative approach. Miles et.al (2014, p.11) posit that "One feature of qualitative data is their richness and holism, with strong potential for revealing complexity". A classical anthropologist, Geertz (1973) buttresses this assertion by noting that thick descriptions are clear, nested in a real context, and has a ring of truth that has a strong impact on the reader. This richly unquantifiable data will include features such as settlement patterns, natural resources, social networks of kinship relations, customary beliefs and practices, personal life histories, and so on (cf.Haviland, Harald, McBride \& Walrath, 2014).

\subsection{Data Collection Methods}

For primary data, the researcher used three fundamental data gathering techniques; participant observation, interviewing and focus groups.

\subsubsection{Participant Observation}

Hennink, Hutter \& Bailey (2011), view participant observation as "The process of learning through exposure to or participation in the day-to-day or routine activities of participants in the research setting." Through participation in the daily activities of the community being studied, the researcher was better placed to learn about the behaviour of individuals in the community and also about the social order within a community, and the cultural norms. As the researcher got involved in the community, he began to shape a relationship with the research participants in the location. This sentiment is reinforced by Kumar (2011). He extrapolates that the main advantage of participant observation is that the researcher spends sufficient time with the group or in the situation; he acquires much deeper, richer and more accurate information.

\subsubsection{Interviewing}

Asking questions is fundamental to ethnographic fieldwork and it takes place in informal interviews (unstructured, openended conversations in everyday life). Informal interviews may be carried out at any time and in any place-on horseback, in a canoe, by a cooking fire, during ritual events, while walking through the community with a local inhabitant and the list goes on (Haviland et al. 2014). The researcher firmly believed that such casual conversations would enable informants to talk freely to him and divulge data as much as they could. He anticipated that the informants would elaborate on answers.

\subsubsection{Focus Groups (Group interviewing)}

Focus groups were also used during data gathering. One rationale behind using focus groups throughout the research was that they saved time and money. Focus groups were useful because they tended to allow a space in which people could get together and created meaning among themselves, rather than individually. The main advantage of focus groups 
is that they provide an opportunity to observe a large amount of interaction on a topic in a limited period of time based on the researcher's ability to assemble and direct focus groups. Furthermore, group discussions provide direct evidence about similarities and differences in the participant's opinions and experiences as opposed to reaching such conclusions from post hoc analyses of separate statements from each interviewee (Babbie \& Mouton, 1998).

\subsection{Sampling Procedure}

The purpose of sampling in qualitative research is designed either to gain in-depth knowledge about a situation, event, and episode or to know as much as possible about different aspects of an individual on the assumption that the individual is typical of the group and hence will provide insight into the group (Kumar, 2011).

\subsubsection{Population}

In Castillo's (2009) views, all research questions address issues that are of great relevance to important groups of individuals known as research population. He emphasizes that a research population is generally a large collection of individuals or objects that is the main focus of a scientific enquiry. Castillo (2009) strengthens this claim by noting that all research population is also known as a well-defined collection of individuals or objects known to have the same characteristics. All individuals or objects within a certain population usually have common binding characteristic. Based on the foregoing description of population, the researcher considered all active and sedentary peasants at Gqumahashe to be the population of the study. It was anticipated that retired peasants would offer a comprehensive historical perspective on a research question.

\subsubsection{Sampling Frame}

A sample frame is a comprehensive list of all units or elements in the target population (Rensburg, 2009). An adequate sampling frame should not exclude any element of the population (Polit \& Beck, 2008 in Rensburg, 2009). The sampling frame for this research was a list of all active peasants and retired peasants taken from the chairperson of residents' association.

\subsubsection{Sample Size/ Unit of Analysis}

In any social science research, a sample is selected from among the data that might be gathered and studied. Babbie (2013) alludes to the fact that the sampling of information occurs in everyday life and often produces biased observation. The significance of sampling is that the researcher can decide how many informants to choose from the total number of the target population. The sample size for this study consisted of 20 informants, 15 active peasants and five retired peasants.

\subsubsection{Sampling Method}

Sometimes it's appropriate to select a sample on the basis of knowledge of a population, its elements, and the purpose of the study. This type of sampling is called purposive or judgemental sampling (Babbie, 2013, p.128). Drawing on Maree's (2007) scholarship, this sampling method involves nothing but purposely handpicking individuals from the population based on the authorities or the researcher's knowledge and judgment. This study made use of purposive or judgemental sampling. This is because the researcher knew very well the study population.

\subsection{Data Analysis}

In examining social research data, the researcher adopted cross-case analysis approach. This is the approach recommended by Babbie (2013) for qualitative analysis. It has two strategies; variable-oriented analysis and caseoriented analysis. This study adopted variable-oriented analysis. It refers to an analysis that describes and/or explains a particular variable. Case- oriented analysis aims to understand a particular case or several cases by looking closely at details of each. The researcher looked for patterns appearing across several observations that typically represent different cases under study. To make this point clear, Babbie (2013) contends that the focus in cross-case analysis is on interrelations among variable, and the people observed are primarily the carriers of those variables. 


\section{Scholarship Review on Social Relations and Crop Production}

The sociology and anthropology of food have recently become very fashionable places to work, with large volumes of books, articles and papers erupting from the academy. This emerging concern with food has sent these new researchers off in all directions; to study the rise of national cultures and national cuisines; to examine processes of reification, colonization and the social relations of labour surrounding the process of food production; to reassess the issue of authenticity and inauthenticity in cuisine; to analyze the role of commodification and market pressures; to investigate more fully the pathologies of anorexia, bulimia and over-eating; as well as the newly-discovered old investigation of the daily practices (Wilkes, 2006).

The foregoing fundamental claim is in line with the views held by Gumerman (1997). He asserts that cultural anthropologists have a long practice of reviewing the social and symbolic roles of food. He ascertains that early research focused on food taboos, and sacrifices, often emphasizing the religious aspects of food. Gumerman (1997) proceeds to argue that this curiosity later twisted to the serviceable aspects of food, particularly the value of food in developing and maintaining social relations. To broaden this assertion, Gumerman (1997) reports that Radcliffe- Brown (1922, p.270) viewed food as means of regulating the social system. He focused on rituals involving food, stressing the social function rather than religious event.

The centrality of traditional crops in enhancing social relations among the Shona was succinctly captured in the Shona saying, 'ukama igaswa hunozadziswa nekudya' (relationships are on their own never adequate, they are only made adequate by people sharing food). Among the Shona, a person who could produce more food and, thus, had some to share with his/her neighbors was always held in great esteem. Such a person had more friends and relatives. By contrast, a person who was not prepared to share food with others was considered not to like those with whom he/she did not share food with. Traditional grain crops, which provided not just the staple food for the people, but also the much cherished traditional beer, were thus a key factor in promoting social relations among the people (Hamutyinei \& Plagger, 1987).

\subsection{Isahlulo (Share-cropping)}

Share-cropping is a type of land tenancy in which the payment for the use of land, the rent, is a percentage of the total physical output obtained in the crop season. Since this proportion is fixed in advance, the absolute quantity of rent varies with the level of harvest. In this and its other attributes, share-cropping differs from cash tenancy, from own use of freehold land, from customary land tenure, and from direct wage labour (Ellis, 1993, p.147).

In 2007, Hebinck \& Lent made a similar point. The findings of their study at Guquka (10km away from Gqumahashe) in Alice district suggested that the prevalent share-cropping (isahlulo) pre-arrangement was that the land owner made accessible his plot to the sharecropper who was in authority for all other factors of production. In return title holders usually claimed half of the harvest crop, but in some cases they demanded 50 to $60 \%$ (Hebinck \& Lent, 2007). The foregoing researchers observed at Guquka that the period share-cropping arrangement was limited to a particular production session.

Another recent similar perspective has been provided by Todaro \& Smith (2009). The argument advanced by the latter is that share-cropping takes place when a farmer uses the landowner's farmland in exchange for a portion of food output, such as half of the rice or wheat grown. The landlord's portion may differ from less than a third to more than twothirds of output, depending on local labor availability and other inputs (such as credit, seeds, and tools) that the landlord provides.

The poor incentive structure of share-cropping lends itself to inefficiency. Alfred Marshall observed that the farmer was in effect paid only part, rather all, of his marginal product and would rationally reduce work effort accordingly (Marshall, 1920). This view was challenged in the 1960s by Steven Cheung, who argued that profit-maximizing landlords would establish contracts requiring adequate work effort from the tenants as well as stipulating each party's share of the output. If, as Cheung argued, effort is not too difficult to monitor, then if one tenant failed to live up to his part of bargain, he would be replaced by another tenant who was willing to work harder; as a result, share-cropping would be as efficient as any other contractual form. Cheung's theory is known as the monitoring approach, in contrast to Marshallian approach (Cheung, 1968).

Ellis (1993) reasons that share-cropping has tended to be regarded as a thought-provoking theoretical puzzle by neoclassical economists and as a domineering form of mistreatment by some Marxian economists. For Ellis (1993) the riddle of share-cropping exists in the incompetence of ordinary economic analysis to explicate certain aspects of its existence as an institution, viz.: 
(a) Certain grounds for suspecting that it may be less efficient and less open to innovation than other kinds of farm tenancy;

(b) Its historical persistence and its coexistence, often in the same locations, which cash tenancy and wagelabour farming;

(c) Customary crop shares between landowner and tenant (e.g. fifty-fifty) which cannot be explained by optimizing criteria alone (Ellis, 1993, p.147).

In the opinion of Ellis (1993), the exploitation view originates from the way it focuses economic power in the hands of landowners, and the control this provides them over the source of revenue of tenants and landless workers.

\subsection{Ilima (Work- parties)}

Beach (1983) discovered that crop production among Shona people was mostly labor intensive. He noticed that the processes of land preparation and sowing in an age when ploughs were still mainly unknown, weeding or hoeing, harvesting or reaping, threshing, and winnowing were such that any one person working unaided would not understand much achievement as work processes tended to be sluggish and challenging.

As an approach towards work and especially more towards the production of grain crops, cooperation was the engine for social cohesion among the Shona people. Philosophical ideas (largely couched in the form of Shona proverbs)

such as 'kuitamushandirapamwesamajuru' (to work together like ants (in building an anthill)), 'charachimwehachitsvanyiinda' (one finger cannot squash louse), 'kucherambevakukomberana' (to dig mice is to encircle them), 'rumerimweharikombichuru' (one man does not surround an anthill), 'kuturikadengarembakubatirana' (to put up a roof to a hut is to assist each other) and 'zanondegaakasiyajiramumasese' (know- all left his/her blanket in the dregs of beer) were all developed as ways of encouraging cooperative work among the people (Hammutyinei \& Plagger, 1987).

According to Bhila (1982), work- parties among Shona farmers were of two different, but closely connected, forms. The first of these was 'humwe' (beer work parties). 'Humwe' was regularly known as 'hoka', 'nhimbe', or 'jakwara'. In 'humwe', an individual seeking to get the assistance of others in his/her work brewed some beer and prepared some food for the workers. The findings of the research of Bhila (1982) revealed that 'humwe' made the work process a social event akin to a feast in which the workers celebrated (and made merry) at the same time as they executed some serious work business. Although 'humwe'could be called for other work processes, such as the thatching huts or fencing of homesteads, it was largely an approach used in the production of grain crops. 'Humwe' could be called for all the stages in the circle of grain production, from cutting down trees, digging the land, sowing the crops, and weeding the crops, to harvesting the crops. 'Humwe' was also called for such work as the threshing of the harvested crops and with the winnowing of the threshed crops (Bhila, 1982).

Another researcher who studied social relations and crop production among Shona farmers was Gombe (1998.) He also believed that work- parties among Shona were in two connected forms. For Gombe (1998), the second of the work processes in the production of traditional grain crops among Shona farmers was 'majangano' (none beer work parties). 'Majangano' functioned as a simple labor exchange programme in which members took to the work of each household in turn without the host having to prepare beer (and in some cases, even food). A generous host could, however, still make some provisions for his/her guests.

Gombe (1998) advises that although 'majangano' could be used in all the stages of grain production, much like 'humwe', the work process tended to find favor with the last stages of production involving threshing and winnowing of grains. The two stages marking the end of the farming season required the farmers to remove their crops from the temporary holding places (usually bare rock on which threshing took place) to the more durable granaries before livestock could be allowed to roam freely in the fields during the dry season. 'Majangano', which did not involve the cumbersome process of preparing beer, thus enabled for speedy removal of crops from insecure temporary holding places to which even thieves could wreak havoc if the crops were not quickly removed to secured places.

The two work processes, 'humwe' and 'majangano', not merely brought people together in the production of food, but also accorded the people the opportunity to socialize on a wide range of issues concerning their society. Bhila (1982) argues that 'humwes' and 'majanganos' for example, afforded members of the community the opportunity to part jokes and to tease each other at the same time as the people worked. Jokes and teases were all hallmarks of a sharing and peace loving society. Jokes and teases helped to remove tension and suspicions likely to lead to conflicts in a society.

Other than jokes, the work processes often provided the opportune moment for which corrective measures could be taken against the erring members of the society. For example, those known to beat their wives or to do some such other antisocial activities could be rebuked either directly, by the elders during the rest sessions at work, or indirectly, through song about their bad habits during the work session. If a member, on realizing that the song was directed at 
his/her bad ways, showed anger, he/she would be reminded in the Shona parlance that 'anyumwaberenderake' (he who suspects a hyena is his/hers). This was Shona adage to show that only the guilty got offended or angry when evil things are mentioned. It was something akin to the old men getting discomfort at the mention of dry bones for fear it implies their imminent death. The teases, however, enabled members of the society to know that their bad habits were known to the society and hence the need for them to make drastic reforms for them to remain acceptable as members of the community. It is important to note that such corrections of bad habits during the work processes were meant to prevent the bad habits from getting worse to the extent of warranting the attention of the chiefs. If such was to happen, the members risked being fined or even being banished from the area (Bhila, 1982).

Apart from the above views, Gelfand (1979) postulates that the work parties also provided opportunities for the socialization of young members of society into adulthood. They were socialized into the importance of cooperative effort and the dangers of separatist work effort. Among the Shona, as Gelfand (1979) noted, even the children are taken out to the fields and each one works according to his/her ability, even if it only means looking after the baby as the elders are working. Laziness, with its potential to create a generation of misfits in society, such as thieves and robbers, was greatly discouraged among the children

The work sessions thus created important platforms for the socialization of the youngsters into the ways of the society. Other than being trained into the ways of work during the work sessions, children also learned more about their kith and kin through the processes of interaction as the elders related to each other during the work session. Ideas relating to respect, especially for the elders, were largely cultivated during the work sessions. During these sessions, elders were at liberty to send children, irrespective of who the parents were, on errands. Any child that showed signs of unwillingness upon being sent by an elder got rebuked. Children were taught to respect all elders as if they were their own 'fathers and mothers' (Gelfand, 1979).

Data of the study conducted by Monica Hunter among the Pondos of former Transkei in 1961 suggest that a woman communicates with her husband when she wishes to make an ilima. Subsequently, she informs her neighbours that in such field on such day there will be an ilima (with meat or beer). The findings of Monica's study reveal that attendance of an ilima among the Pondos is not compulsory, people attend voluntarily. While interacting with her study population Hunter (1961), observed that on the morning of the day the owner of an ilima is the first person to be in the field. Her neighbours join her immediately and commence work. Other people join them as the day progresses. Monica also noticed that a pig or goat is butchered at noon if an ilima is for meat and all present workers share in the feast. When an ilima is for beer, a quantity is taken to the field for the workers to drink there, then after work they return to the umzi of the owner of the field and drink the rest of the beer in her hut (Hunter, 1961, p.88).Another interesting point about Monica's fieldwork evidence is that an ilima with beer always attract more people than an ilima with meat due to the fact that by summer the beer is scarce and people do anything to get it (Hunter, 1961).

In 1985, Kuckertz studied the role of work- parties among the farmers of Caguba, Mthwa administrative area of Western Mpondoland, former Transkei. Kuckertz discovered that any work related to the homestead could involve more work than the household's own labour resources could cope within a limited time, like house- building or the fencing of a garden. The homestead head has then to make special efforts to mobilize a labour force from outside his homestead: people want to 'speed up' (ukukhawulezisa) things, as the popular phrase puts it. Kuckertz discovered that there were basically two types of work-party in Caguba: one is called isitshongo or umnoyisho, the other ilima (plural amalima). The noun isitshongo is propably related to utshongo which means 'roasted maize', umnoyisho is derived from Afrikaans nooi, meaning 'to invite'. The word ilima derived from the verb ukulima, which means 'to dig, plough, cultivate' (Kuckertz, 1985). These types vary in three respects: the manner of inviting participants, the differing function of beer, and size.

If a homestead head intends to organize an isitshongo-type work party, he will announce the forthcoming event at a suitable public meeting, such as a public celebration or any large gathering of people. An isitshongo may attract up to 200 people (Kuckertz, 1985). One of the interesting points about the findings of Kuckertz's study was that the advantage of an isitshongo was that the larger number of participants would be able to hoe a bigger field in a shorter time, or cut all the poles and wattle for a new house. However, Kuckertz (1985) also noticed that there was the disadvantage: an isitshongo required heavy expenditure on the part of the organizer, while the quality of the work is poorer than that of an ilima, owing to greater consumption of alcohol.

Kuckertz (1985) continues to remark that:

"Unlike the isitshongo, an ilima is rarely (if ever) publicly announced. Instead, the homestead head (his wife or a senior daughter) will go and invite certain individuals to come and help him; he will ask for assistance (ukucela uncedo). When the homestead head thus invites workers, he does not need to explain that food (i.e. beer) will be provided. This is common practice; but, generally speaking, less beer is served to an ilima than to an isitshongo, and beer functions 
hardly at all as an incentive to give the requested assistance. Finally, the more common ilima is smaller in number than the isitshongo; it has seldom more than twenty to twenty five participants".

According to Kuckertz (1985), what all ilima work-parties have in common is that they involve a series of personal invitations, because in no case can the organizer rely on the assumption of mutual benefit .An individual cannot assume that people will know that he is having a work-party and that some of them will come and help him in the hope that of receiving help in return.

In 2005, Patrick McAllister also studied work-parties in Shixini, coastal former Transkei. The argument he develops on the basis of his research is that farmers at Shixini develop forms of co-operative work in their attempts to maintain homestead production as part of their strategies to secure livelihood. McAllister discovered that most daily work in Shixini was undertaken by members of an individual homestead, but close neighbours often assist each other informally with many tasks. Members of a small number of neighbouring homesteads sometimes agree to help each other on a reciprocal basis and such work in inconspicuous, not in the public eye. A more formal but uncommon way of organizing neighbourhood labour is referred to as an umbutho (a 'regiment'). It consists of a group of around eight adult women who agree to work for each other on variety of tasks on reciprocal basis (McAllister, 2005, p. 215).

Many homesteads do not enter formal reciprocal alliances but nevertheless co-operate extensively with neighbours by participating in work-parties based on ad hoc requests for assistance. A small work group of this kind is called an isicelo (a request, from ukucela, 'to ask for something'). Neighbours, friends or nearby kin are asked to help with a task and provided with beer or some other items as a reward. The reward is not payment, but a necessary incentive and a sign that the work is appreciated. Failure to heed the request to assist without a very good reason in interpreted as a breach of friendship and good neighbourliness, and those who participate anticipate that they, too, will receive assistance when they ask for it (McAllister, 2005).

Another way of securing labour through the provision of goods is to invite people to partake of a commodity in return for labour. For example, it is common practice for a homestead head to kill a 'pig for hoeing' (ihagu yokuhlakula), and to announce that meat is available. The latter approach is similar to the one observed by Monica Hunter among the Pondos of former Transkei in 1961. Individuals who take up the offer agree to hoe for a certain number of days in return. This is more than an acceptance of payment for labour, it is also friendly neighbourly act which people expect from those they have a close relationship with and which ought to be reciprocated with labour (which will in turn elicit a material reward) at a later date (McAllister,2005,p.216).

In the opinion of McAllister (2005), perhaps the most important form of co-operative work in Shixini is what is known as the ploughing or farming 'company' (inkampani yokulima). This comprises of from four to twelve homesteads, which combine their labour, implements and draught cattle to execute farm duties such as ploughing, planting and, to a lesser extent, harvesting. Without them agricultural activity in Shixini would be problematic to sustain, and most homesteads belong to one. Work is done for each member in turn every season, and a member who fails to contribute as expected can be expelled from the group. Some companies are based primarily on agnatic kinship, and justified in terms of kinship obligations. Most, however, include members of a variety of kin groups within a common locality.

During his research, McAllister (2005) learnt that the morality of reciprocal exchanges of labour was conceptualized in terms of good neighbourliness (ubumelwane), which literally means 'supporting each other'),mutual assistance (ukuncedana) and human-ness (isintu). They are spoken of as isiXhosa ('the Xhosa way'), 'the way we live together as people', or 'the way we live as Xhosa'. They are part of rural ethos in terms of which, as the old Xhosa proverbs have it, 'one hand washes the other' (isandla sihlamba esinye) and 'a person is a person by means of (other) people' (umntu ngumntu ngabanye abantu).

\section{Research Results}

In relation to the proposition of Hebinck \& Lent (2007), the findings of the study reveal that sharecropping is favoured and virtually the only institution that allowed land transactions to take place between land owners and non-land owners at Gqumahashe.

The data gathered during the investigation proves that sharecropping (isahlulo) is a deep-rooted practice in the study area. When asked why they (informants) were engaged in sharecropping, they reported that they practice sharecropping due to the following reasons:

(a) They are incapable to cultivate all their land themselves due to no oxen, no plough or no seed;

(b) They are far away from the village employed elsewhere (migrants);

(c) They have no land of their own or; 
(d) They wish to increase the amount of land they have under cultivation, and thus increase their harvest or;

(e) They wish to plough a more fertile piece of land or land where trespassing stock will not damage their crops.

During sojourns to Gqumahashe, it was discovered that labour combinations are also sometimes essential for various heavy or time-consuming tasks like ploughing (ukulima), forest clearing (ukugeca imithi) and hoeing (ukuhlakula).

At the time of interviews Gqumahashe informants reported that a farmer just enlists the help of his neighbours who work for him during one or more days in the agricultural season, in the knowledge that he would do the same for each of them when their turn came to call upon his services. The findings of the study at Gqumahashe with regard to the role of work- parties reinforce those of McAllister (2005) in Shixini village. Local farmers highlighted that work-parties were desirable in their farming activities as they were aimed at helping one another (ukuncedana). They reported that a principal advantage of work-parties was that it includes a substantial laborious work to be done quickly.

\section{Conclusion}

It became clear in the research that sharecropping occur extensively in the study area. It has benefits for both owners and the croppers. It encourages the cropper to remain on the land throughout the harvest season to work on the land, solving the harvest rush problem. On the other hand, sharecropping is viewed as a form of exploitation. The exploitation view stems from the fact that it concentrates economic power in the hands of landowners, and the control this gives them over the livelihoods of tenants and landless workers (Ellis, 1993). The same fundamental issue is raised by Todaro et.al (2009) who observed that the farmer was in effect paid only part, rather than all, of his marginal product and would rationally reduce work effort accordingly.

From general observations and discussions with farmers of the studied community, it became clear that cooperative labour in the form of 'work-parties' or other forms of partnership between local farmers play a significant role in the agricultural sector. The research evidence suggests that Gqumahashe farmers engage themselves in co-operative work in situations where labour and cash are rare and where there are shortages of resources such as draught animals or implements.

Based on primary data and secondary data, this article concludes that work-parties among the peasants cultivate the spirit of "oneness" or togetherness. Work -parties bring people together. The sentiment put forward in the literature is that mutual helpfulness and reciprocity is the root of work-parties. Co-operative work binds people in affable social relations, especially relations of production (Tavuyanago et.al., 2010). If there are no norm of reciprocity and assumption of mutual helpfulness, asks Kuckertz (1985), how is social cohesion maintained, how does society hang together? According to Kuckertz (ibid) the society hangs together because the organizer of the work party will, at a different point in time, help others when he/ she is asked. Long and short-term dimensions (morality and interest) are interwoven to provide social unity over time.

\section{References}

Andreatta, S. \& Ferraro, G. (2012). Elements of culture: An applied perspective. Wadsworth: CENGAGE Learning.

Babbie, E. (2013). The practice of social research.

Babbie, E. \& Mouton, J. (1998). The practice of social research. Cape Town: Oxford University Press.

Beach, D.N. (1983). The Zimbabwean plateau and its people. In: Birmingham. D. \& Martin, P.M. (Eds). History of Central Africa, volume one. London: Longman.

Bhila, H.H.K. (1982). Trade and politics in a Shona Kingdom: The Manyika \& their African \& Portuguese neighbours.1575-190. Salisbury: Longman.

Brown, L.K. \& Mussel, K. (Eds). (1984). Ethnic and regional foodways in the U.S: The performance of group identity. Knoxville: University of Tennessee Press.

Castillo, J.J. (2009). Research population. (Online) Available from:http://explorable.co.research.com.reseach population.[Accessed: $4^{\text {th }}$ February 2013].

Cheung, S. (1968). Private property rights and sharecropping. Journal of political economy.76-1107-1122.

Coe, S.D. (1994). America's first cuisines. Austin: University of Texas Press.

Douglas, M. (1971). Deciphering a meal. In Geertz, C. (Ed). Myth, Symbol and culture. New York:W.W.Norton.

Ellis, F. (1993). Peasant economics: Farm households and agrarian development (2 ${ }^{\text {nd }}$ edn). Britain: Cambridge University Press.

Geertz, C. (1973). Thick description: Toward an interpretive theory of culture. In The interpretation of cultures (pp.3-30). New York: Basic Books.

Gelfand, M. (1979). Growing up in Shona society. Gwelo: Mambo Press.

Gombe, J.M. (1998). Tsika DzavaShona.(2nd edn). Harare: College Press.

Gumerman, G. (1997). Food and complex societies. Journal of Archaeological method and theory. 4(2). 
Hamutyinei, M.A. \& Plagger, A.B. (1987).Tsumo-Shumo: Shona proverbial lore and wisdom. Gweru: Mambo Press.

Haviland, P., Prins, H.E.L., McBride, B. \& Walrath, D. (2014). Cultural Anthropology: The human challenge. (14th edn). Wadsworth: CENGAGE Learning.

Hebinck, P. \& Lent, P.C. (Eds). (2007). Livelihoods and landscapes: The people of Guquka and Koloni and their resources. Boston: Brill Leiden.

Hennink, M., Hutter., \& Bailey, A. (2011). Qualitative research methods. London: SAGE Publications.

Hunter, M. (1961). Reaction to conquest: Effects of contact with Europeans on the Pondoland of South Africa(2nd edn) . London: Oxford University Press.

Kuckertz, H. (1985). Organizing labour forces in Mpondoland: A new perspective on work parties. Africa: A journal of African Studies.

Kumar, R. (2011). Research methodology:A step-by step guide for beginners.(3rd edn). Washington DC: SAGE Publications.

Maree, K. (2007). First steps in research. Pretoria, South Africa: Van Schaik Publishers.

Marshall, A. (1920). Principle of economics ( $8^{\text {th }}$ edn). London: Macmillan.

McAllister, P. (2005). Xhosa co-operative agricultural work groups: Economic hindrance or development? Social Dynamic: A journal of African Studies. 31(1) 208-234.

Mennell, S. (1985). All manners of food: Eating and taste in England and France from the Middle Ages to the present. Oxford: Basil Blackwell.

Miles, M.B., Huberman, A.M., \& J. Saldana (2014). Qualitative data analysis: A methods sourcebook. (3rd edn). Thousand Oaks: SAGE Publications.

Peopls, J. \& Bailey, G. (2012). Humanity: An introduction to cultural Anthropology.(9th edn). Wadsworth: CENGAGE Learning.

Radcliffe- Brown, A.R. (1922). The Andaman Islanders. New York: Free Press.

Remenyi, D. \& Money, A. (2012). Research supervision for supervisors and their students.United Kingdom: Academic Publishing International Limited Reading.

Rensburg, G. (2009). Research in social sciences. Pretoria, South Africa: Muckleneuk.

Tavuyanago, B., Mutami, N., \& Mbenene, K. (2010). Traditional grain crops in pre-colonial and colonial Zimbabwe: A factor for food security and social cohesion among Shona people. Journal of Sustainable Development in Africa.12 (6).

Todaro, M.P. \& Smith, S.C. (2009). Economic development.(10th edn). Essex: Pearson Education Limited.

Wilkes, S. (2006). The social relations of food. Oxford: Forum on public policy. 